\title{
ANCIENT GREEK MATHEMATICO-PHYSICAL PARADOX
}

Glenn W. Erickson, Ph.D.* John A. Fossa, Ph.D.**

SÍNTESE - Neste artigo revisa-se a literatura sobre paradoxos matemático-físicos gregos antigos. Trata-se de paradoxo de números irracionais, o dilema de Democritus, a antinomia de mudança, bem como os seguintes paradoxos de Zenon: a dicotomia, o Aquiles, os blocos móveis, o argumento contra a pluralidade, 0 dilema e a semente de painço.

Palavras-chaves: Paradoxo, Matemática, Zenon.
ABSTRACT - The paper is a review of literature about a number of ancient Greek physicomathematical paradoxes, including the paradox of irrational numbers, the antinomy of change; Democritus' Dichotomy, as well as the following of Zeno's paradoxes: the Dichotomy, the Achilles, the Arrow, the Moving Blocks, the argument against plurality, the Dilemma, and the Millet Seed.

Keywords: Paradox; mathematics; Zeno.

\section{1 - Introduction}

Zeno of Elea (born c. $490 \mathrm{BC}$ ), a disciple of Parmenides, is the most famous paradoxer of all time. Zeno's basic strategy was to disprove positions contrary to the Parmenidean insight that since only the unchanging. One exists, nothing in reality can change. He proposes a series of arguments purporting to show that the concepts of motion (change), the many (plurality), and place (space) were inherently contradictory and led to absurdities.

Aristotle's Physics attributes to Zeno four mind-boggling paradoxes against motion: first, the Dichotomy, the Race Course, or the Bisection Paradox (section 3 below); second, the Moving Blocks, or the Stadium, (section 4); third, the Arrow (section 5); and fourth, the Achilles, or Achilles and the Tortoise (section 6). The Arrow and the Moving Blocks are generally interpreted to be predicated upon the assumption that space and time are composed of finitely sized indivisibles or atomic quanta. The Achilles and the Dichotomy, by contrast, presuppose that space and time are composed of infinitesimal points. Thus, whatever may be one's pleasure in regard to the philosophy of space and time, the very concept of motion will purportedly still land one in inextricable difficulties.

* Universidade Federal de Santa Maria, UFSM.

* Universidade Federal do Rio Grande do Norte, UFRN.

\begin{tabular}{|l|l|l|l|l|l|}
\hline VERTTAS & Porto Alegre & v. 41 & $n^{0} 164$ & Dezembro 1996 & p. $681-690$ \\
\hline
\end{tabular}


Less well known than the paradoxes against motion are Zeno's paradoxes against plurality (section 7), and his paradox against place, which Aristotle calls Zeno's Dilemma (section 8). The Millet Seed (section 9), which attempts to discredit sense knowledge, is, in contrast to his more subtle paradoxes, an easily controverted pseudo-paradox. It was because of these arguments that Aristotle calls Zeno the inventor of dialectics.

Beyond Zeno's paradoxes, we treat three other physico-mathematical paradoxes: the Paradox of Irrational Numbers (section 2); the Paradox of Change (section 10); and Democritus' Dilemma (section 11). The first emerged in early Pythagoreanism, the second is a physical paradox, and the third developed in the context of ancient Greek geometrical method.

\section{2 - The Paradox of Irrational Numbers}

To the man on the street, it is the Pythagorean belief that the world exhibits an intrinsically rational structure that is paradoxical, not the discovery of irrational number that so scandalized the Pythagorean school. The early Pythagoreans thought that "all is number and harmony." By numbers they meant the positive integers; by harmonies, the ratios and proportions between these integers. Yet not all geometrical relationships can be expressed as ratios between whole numbers. For example, the isosceles right triangle with the two equal sides of one unit has a hypothenuse equal to the square root of two. Indeed, this became the standard example of an "incommensurable" quantity (more precisely: two quantities are incommensurable if they cannot be measured by a common unit), although the original discovery may have been made in the regular pentagon. In any case, geometry played a central role, since line segments are continuous, as opposed to the discrete system of the natural numbers. Hence, the Pythagoreans were faced with an example of something that (for them) really existed, but which could not be explained by numbers and harmonies. Thus the discovery of such "irrational numbers" seriously threatened the Pythagorean conception of the cosmos, their existence being a flaw in an otherwise elegant universe (Von Fritz, 1945). Report has it that when one of their members made the existence of irrational numbers public, he was taken out to sea by the brothers and drowned.

\section{3 - The Dichotomy}

Zeno's first argument against motion, mentioned by Aristotle (1941, 239b 11-13, 263a 4-6) and Simplicius, is as follows: In order for a moving object to reach a distant point, it must always transverse half the remaining distance. Motion is thus impossible because it requires traversing an infinite series of distances one at a time.

Consider a runner heading toward the finish line on a race course. In order to finish the race, he must first reach a point midway between his present position and the finish line. The runner, once he has reached the midway point, still has half the race to complete; but he cannot do so without reaching the three-quarter point, which is halfway between the midpoint and the finish line. The process is repeated without end and, hence, there will always be a residual interval between 
the runner's position and the finish line, making it impossible for him to complete the race. The paradox is often formulated as a regression in the following manner; the runner must first reach the midpoint; but, in order to do so, he must first reach the quarter point; and so on without end. The conclusion would then be not that the runner cannot finish the race, but that be cannot even start.

Gregory Vlastos (1974a) has argued effectively that the original paradox was most likely to have been a progression, as we presented it above. Formulated as a progression, its basic affinity to the Achilles Paradox is readily seen. The argument can be summarized as follows:

(1) Finishing any motion requires crossing an infinite sequence of successive distances.

(2) The crossing of an infinite sequence of successive distances cannot be completed.

(3) Therefore no motion can be finished.

As may be expected, the responses to the paradox have been, in the main, similar to the responses to the Achilles below.

Aristotle, distinguishing between actual infinite and potential infinity, denied premise (1). Charles Chihara (1965) advances similar considerations. In contrast, the majority of modern interpreters deny premise (2), which they take to mean one the following:

(a) Crossing the infinite sequence cannot be done because it would take an infinite amount of time;

(b) Crossing the infinite sequence cannot be done because the sequence has no final member.

In either case, the existence of convergent series (see the Achilles) is used to falsify the premise.

Nevertheless, Leo Groarke (1982) argues that since the runner must traverse the infinite sequence of distances one by one - that is, he traverses them a finite number at a time - he is unable to get beyond a finite number of intervals, regardless of the fact that the series is convergent. Hence, according to Groarke, (b) has not been falsified and the paradox remains a genuine puzzle.

\section{4 - The Achilles}

The Achilles, second of Zeno's arguments against motion runs as follows: "In a race the quickest runner can never overtake the slowest. Since the pursuer must first reach the point whence the pursuit began, the slower must always hold a lead" (Aristotle, 1941, 239b 15-18).

A fast runner (say, brave Achilles) may be set the task of overtaking a slower one (say, a tortoise) that is given a head-start. In order to catch up to the tortoise, however, Achilles must first reach the point which the tortoise had attained when Achilles started after it. Yet during the interval it takes Achilles to reach this point, the tortoise will have advanced to a farther point. Thus Achilles must reach this new point, but by the time he does so the tortoise will have again moved to a new 
position. Hence there is always a residual interval between Achilles and the tortoise and the hero never catches the slow beast.

Since we know from experience that Achilles catches the tortoise in short order, the point of resolving this paradox is to identify the fallacy that makes the paradox plausible. Aristotle distinguishes potential infinity from actual infinity. By the former, he means something like "infinitely divisible". Since space and time are only potentially infinite, the paradox, according to Aristotle, does not arise.

The concept of infinity was troublesome to ancient Greek mathematicians because, in part, they did not have the concept of a limit. C. S. Peirce and A. N. Whitehead (1929) are among those who have used the idea of a limit to resolve the paradox. According to this view, Achilles' predicament can be reduced to a convergent infinite series, such as

$$
1 / 2+1 / 4+1 / 8+\ldots+1 / 2^{n}+\ldots
$$

The limit of this series is simply one. Max Black (1951) argues, however, that the existence of a finite limit of an infinite series is not sufficient to resolve the paradox because it does not obviate the necessity of Achilles performing an infinite number of acts.

J. M. Hinton and C. B. Martin (1953) contend that the paradox depends on an ambiguity. On the one hand, the description of the paradox merely requires Achilles to pass through all the intermediary points between his starting point and the point at which he overtakes the tortoise and this causes no further complications. On the other hand, the paradox may be interpreted as a series of commands restricting Achilles movements in certain ways. The first interpretation, according to Hinton and Martin, verifies the premise of the paradox but invalidates the argument. In contrast, the second interpretation validates the argument, but falsifies the premise.

\section{5 - The Arrow}

Mentioned by Aristotle, Epiphanus, and Diogenes Laertius, the Arrow is the third of Zeno's arguments against motion.

"An Arrow in flight is motionless because it is always occupying a space equal to itself at each moment and because everything that occupies an equal space is at rest" (Aristotle, 1941, 239b 5-7).

Zeno "argues thus: what is moving moves either in the place in which it is or in the place in which it is not. And it moves neither in the place in which it is not in that which it is not. Therefore nothing moves" (Epiphanus, Adversus Haereticos, III.11; cited in Lear, 1981, n. 1)

Anything that occupies a space its own size is at rest. An arrow in flight, while it is in flight, exists in a present moment. Yet in that present moment the arrow occupies a space just its own size. Thus in the present moment the arrow is at rest. Yet that means that a moving arrow is also at rest, which is absurd.

The Arrow is generally considered to be predicated upon the assumption that time consists of non-instantaneous atomic intervals (for another view, see Vlastos, 1974b). Indeed, the paradox does not seem to arise when time is conceived of as a succession of instantaneous moments since movement is dependent on velocity. 
But velocity is the ratio of distance (change in position) to elapsed time and there is no elapsed time at a point-like moment. Hence it would seem that the very concepts of rest and motion would not be applicable to an object at an instantaneous moment. Jonathan Lear is probably correct in asserting that the extension of the concept of velocity to instantaneous velocity by the concept of 'limit' is irrelevant to the paradox.

Aristotle used the idea of velocity to argue that the concepts of rest and motion are not even applicable to atomic intervals since, by considering objects with different velocities, it would be possible to divide the atomic interval. Denying that motion is inconsistent with the atomicity of time, however, would seem to be but a hollow victory for, on the present view, that was Zeno's purpose anyway moreover, Zeno is armed with other paradoxes purporting to show that motion is also inconsistent with instantaneous time. A possibility apparently not discussed in the literature is that a moving arrow might effectively fill a larger amount of space than an arrow at rest. Thus, the paradox would fail because it would contain a false (ambiguous) premise; nevertheless, motion and atomic time would not be contradictory. Lest this hypothesis be considered more paradoxical than the paradox itself, we hasten to add that the Lorentz-Fitzgerald contraction of Relativity Theory could be used to the same purpose. Similar theories appear in quantum theory.

\section{6 - The Moving Blocks}

For the Moving Blocks, the fourth and last of Zeno's arguments against motion, this paradox is also called the Stadium, our source is Aristotle (1941, 239b 33-240a 17).

The fourth argument is that concerning the two rows of bodies, each set being composed of an equal number of bodies of equal size, passing each other on a race-course as they proceed with equal velocity in opposite directions, the one row originally occupying the space between the goal and the middle point of the course and the other that between the middle point and the starting-post. This, he [Zeno] thinks, involves the conclusion that half a given time is equal to double that time.

Aristotle's telegraphic style makes the paradox difficult to decipher. Nevertheless, the basic structure of the action in the paradox is easily seen. Body A moves its own length (say, a unit) to the right, while Body $B$, equal in length and vertically aligned with Body $A$, moves its own length to the left (see figure).

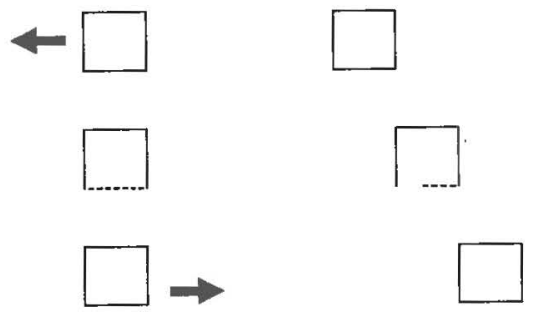

First Instant Next Instant 
Relative to the stationary ground $\mathrm{C}$, Body $\mathrm{B}$ has moved a unit in a given amount of time $t$. Relative to Body A, however, Body B has moved a distance of two units in the same time $t$ and, therefore, it has moved a single unit in time $t 12$. Since both $t$ and $t 12$ are the times that Body B took to move a single unit of distance, we have that $t-t 2$; that is, "half a given time is equal to double that time".

The fallacy involved in this paradox is, at first sight, all too obvious. As Aristotle explains, "the fallacy of the reasoning lies in the assumption that a body occupies an equal time in passing with equal velocity a body that is in motion and a body of equal size that is at rest". There is, however, an alternative interpretation first proposed by Paul Tannery (1885), according whom, the time $t$ is an atomic quantum of time. The argument then proves that Body B, relative to Body $A$, would traverse the unit length (perhaps itself an atomic quantum) in one-half the atomic quantum of time, thereby dividing a supposed indivisible. Although Tannery's interpretation makes the paradox veridical instead of ridiculous, Vlastos (1967) rejects it on the grounds that it has not been documented in historical sources.

\section{7 - Zeno's Arguments against Plurality}

Zeno authored a number of paradoxes against plurality. The general form of these arguments is that if there are many things, they must be both infinitely small and infinitely large. Zeno seems to have argued that whatever has size is divisible into parts and, thus, does not possess the unity characteristic of a single thing, as opposed to many things. Hence, none of supposed plurality of things can have any size. In contrast, no amount of sizeless things could produce a body with any size. Hence, the parts of any given body must have some size. Now, since each part is sizable, each part must be divisible into parts having some size. By reiterating the argument for each new part, the body is found to be composed of an infinite number of parts having some size and, therefore, the body must be infinitely large.

Vlastos (1967) points out that though the premise that a thing cannot be a single thing if divisible into parts is undoubtable from the standpoint of Eleatic doctrine, it is in fact false. An apple, for example, has many parts - skin, core, seeds, and what not - but remains for all that but a single thing. Thus, Zeno's conclusion that the many are infinitely small does not follow. Vlastos then invalidates the conclusion that the many are infinitely large by appealing to the modern notion of convergent series. Thus the sum of an infinite number of nonzero sizes may be a finite size and again Zeno's conclusion does not follow.

\section{8 - Zeno's Dilemma}

Zeno's Dilemma, mentioned by Aristotle $(1941,209 \mathrm{a} 23-25,210 \mathrm{~b} 22-24)$, is that either place does not exist or, existing, must have a place in which it exists. Zeno was presumably motivated by a desire to show that the very concept of place is contradictory. He argued that whatever exists must extst in some place. Hence, if 
place exists, place exists in some place. By reiterating the argument for each newfound place, an infinite regress is obtained.

Aristotle resolved the paradox by distinguishing among the various senses of "to be" (there was no separate word for "to exist"). Vlastos (1967), however, points out that Aristotle's solution could not have been advanced in Zeno's time because the required distinctions had not yet been made. Thus the paradox must have been genuinely puzzling to Zeno's contemporaries.

\section{9 - The Millet Seed}

One of Zeno's paradoxes, mentioned by Aristotle (1941, 250a 19-21) and by Simplicius at In Physica 1108, 18-28, the Millet Seed is probably a false or pseudo-paradox. It goes as follows: If a gross of millet seeds makes a noise when it falls, a single millet seed will make a proportionately smaller sound when it falls.

Motivated by an Eleatic prejudice against perception, Zeno is apparently suggesting that if our senses fail us in the case of the fainter sound, we should think twice about believing what our senses register in the case of the louder sound.

Zeno's argument presumes that we should hear disturbances in the air as sounds no matter how slight they are, but there is no special difficulty in the circumstance that our auditory powers are limited in this particular manner.

\section{0 - The Antinomy of Change}

This puzzle, discussed in antiquity by both Plato and Aristotle, challenges our conception of change. Consider an object that is unchanging (in some respect) for a period of time and then undergoes a change (in that respect). At the precise instant that the change starts, is the object unchanging or changing?

The formulation given above is stated in general terms because, as Aristotle pointed out, the paradox applies to all forms of change. Nevertheless, it is probably most easily discussed in terms of motion. Thus consider an object that is originally at rest and at some instant begins to move. At that instant, is the object (still) at rest or (already) in motion? Neither alternative seems satisfactory. Nevertheless, as Joseph Wayne Smith (1986, p. 101) observes, "the real difficulty in our question is as follows. At the point of change it seems that the object in neither in motion or at rest. But if for all objects at all times, they are either at rest or in motion, a contradiction follows."

One response to the paradox would be to agree with Parmenides that the very concept of change is contradictory and, thus, does not occur. Another response concedes the contradiction, but refuses to denigrate sense knowledge by denying change. In this view, however, our theoretical description of change is necessarily convoluted. Still another response, pioneered by Aristotle (1941, Ch. 8, Sec 8), is based on "cuts" in the continuum. Thus, the point of change can be seen in various ways as both (in the case of motion) the last point of rest and the first point of motion, or as the first point of motion whose antecedent period of rest has no last point. Smith argues that none of these solutions are satisfactory and that the only way out of the paradox is to recognize that "nature is arbitrary" (1986, p. 105). That 
is, in each particular case, one or other state is realized by change, as it were. Smith claims further that this result is an incipient indication of free will in man.

Aristotle (1941, VI 3 and 8), following Plato (1961, 156C-157A), however, gives another solution: at the point of change, the object is neither at rest nor in motion. To avoid the paradox, this view necessitates the denial of Smith's premise that "for all objects at all times, they are either at rest or in motion" (Smith, 1983, p. 101). This denial is indeed intuitively satisfying because change is a process; that is, it is something that can only happen over time. "Instantaneous change" would seem, therefore, to involve a category mistake. We also need observe, however, that this discussion does not invalidate such mathematical concepts as "instantaneous velocity" which are technical concepts (involving limits) used to model physical situations.

\section{1 - Democritus' Dilemma}

This mathematical paradox was attributed to Democritus by Plutarch. In the translation of T. L. Heath (1921, p. 179-80), the problem runs as follows.

If a cone were cut by a plane parallel to the base [by which is clearly meant a plane indefinitely near to the base], what must we think of the surfaces forming the sections? Are they equal or unequal? For, if they are unequal, they will make the cone irregular as having many indentations, like steps, and unevennesses; but, if they are equal, the sections will be equal, and the cone will appear to have the property of the cylinder and to be made up of equal, not unequal, circles, which is very absurd.

Democritus seems to think of the cone as being made up of many thin circular disks piled on top of each other; whether he thought there were an infinite number of them is not altogether clear. In any case, if we choose two disks that are indefinitely close to each other, they must be either equal or unequal. If they are unequal, the cone would become tiered, like a wedding cake; but if they are equal, the cone would become a cylinder.

Democritus' response to this problem is unknown. Perhaps more importantly, however, Archimedes attributes to Democritus two theorems about volumes: (1) the volume of a cone is a third of that of the cylinder on the same base and of the same height and (2) the volume of a pyramid is a third of that of the corresponding prism. According to Heath, it is probable that Democritus used the idea of a solid being composed of an infinite number of plane sections in order to obtain these results, thereby anticipating Cavalieri's Principle.

\section{2 - Conclusion}

What all these paradoxes share is the ancient Greek preconception that arithmetic and geometry are wedded to each other in the sense that all valid arithmetic is representable geometrically and that all valid geometry is representable arithmetically. Many of them share the further preconception that the physical world is constituted by such a arithmetic and such a geometry. That these conceptions generate paradoxical results, and why, is not always clear even today. 


\section{References}

ARISTOTIE. Physics. In: The Basic Works of Aristotle. Ed. Richard McKeon. New York: Random, 1941. BLACK, Max. "Achilles and the Tortoise". Analysis 11.5 (1951): 91-101.

CHIHARA, Charles. "On the Possibility of Completing an Infinite Process". Philosophical Review (1965): 74-87.

GROARKE, Leo. "Zeno's Dichotomy: Undermining the Modern Response". Auslegung 9 (1982): 67-75.

HEATH, Thomas L. A History of Greek Mathematics. Oxford: Clarendon, 1921.

HINTON, J. M. and MARTIN, C. B. "Achilles and the Tortoise". Analysis 14.3 (1953): 56:68.

LEAR, Jonathan. "A Note on Zeno's Arrow". Phronesis 26 (1981): 91-104.

PLATO. Parmenides. In: The Collected Dialogues of Plato, including the Letters. Ed. Edith Hamilton and Huntington Cairns. New York: Pantheon, 1961.

SMITH, Joseph Wayne. Reason, Science and Paradox: Against Received Opinion in Science and Philosophy. London: Croom Helm, 1986, Ch. 5.

TANNERY, Paul. "Le concept Scientifique de Continu: Zénon d'Elée et George Cantor". Revue Philosophique de la France et de l'Étranger 20 (1885): 385-410.

VLASTOS, Gregory. "Zeno of Elea". Encyclopedia of Philosophy. Ed. Paul Edwards. New York: Macmillan, 1967, v. 8, 369-379.

—_ ."Zeno's Race Course". Studies in Presocratic Philosofy. Ed. R. E. Allen and D. I. Furley. London: Routledge, 1974a, v. 2, 201-220.

—_ . "A Note on Zeno's Arrow". Studies in Presocratic Philosophy. v. 2. Ed. Allen, R. E., and D. J. Furley. London: Routledge, 1974b, 184-200.

Von FRITZ, Kurt. "The Discovery of Incommensurability by Hippasus of Metapontum". Annals of Mathematics 46 (1945): 242-264.

WHITEHEAD, A. N. Process and Reality. Cambridge: Cambridge UP, 1929, 101-108.

\section{Works consulted}

BENDEGEM, Jean Paul van. "Zeno's Paradoxes and the Tile Argument". Philosophy of Science 54 (1987): 295-302.

BOOTH, N. B. "Zeno's Paradoxes". Journal of Hellenic Studies 77 (1957): 187-201.

BOUWSMA, O. K. Toward a New Sensibility. Lincoln: U. of Nebraska P, 1982, 213-240.

BROCHARD, Victor. Études de Philosophie Ancienne et de Philosophie Moderne. Paris, 1912, 7-9.

CAJORI, F. "The History of Zeno's Arguments on Motion". American Mathematical Monthly 22 (1915): $1-6,39-47,77-82,109-115,143-149,179-186,253-258,292-297$.

DEJNOZKA, Jan. "Zeno's Paradoxes and the Cosmological Argument". Philosophy of Religion 25 (1989): 65-81.

GALE, Richard M., ed. The Philosophy of Time. New York: Anchor, 1968, 387-494.

GRUNBAUM, A. "Messrs. Black and Taylor on Temporal Paradoxes". Analysis 12.6 (1952): 144-148.

- . "Modern Science and the Refutation of the Paradoxes of Zeno". Scientific Monthly 81.5 (1955): 234-239.

—_. Modern Science and Zeno's Paradoxes. Middletown, CN: Wesleyan. UP, 1967.

HAGER, Paul. "Russell and Zeno's Arrow Paradox". Russell 7 (1987): 3-10.

KNORR, Wilbur R. "Zeno's Paradoxes Still in Motion". Ancient Philosophy 3 (1983): 55-66.

KING, H. R. "Aristotle and the Paradoxes of Zeno". Journal of Philosophy 21 (1949): 657-670.

KRETZMAN, Norman. "Aristotle on the Instant of Change". Aristotelian Society Supplement 50 (1976): 91-114.

LEE, Harold N. "Are Zeno's Paradoxes Based on a Mistake?" Mind ns 74 (1965): 563-70.

LEE, H. P. D. Zeno of Elea: A text with Translation and Notes. Cambridge UP, 1936.

McKIE, John R. "The Persuasiveness of Zeno's Paradoxes". Philosophy and Phenomenological Research 47 (1987): 631-639.

MLL, J. S. System of Logic. 5th. ed. 389-390.

OWEN, G. E. L. "Zeno and the Mathematicians". Proceedings of the Aristotelian Society 58 (1957-58): 199-222.

ROSS, W. D. Aristotle's Physics. Oxford, 1936, 81-82.

ROSSETTT, Livio. "The Rhetoric of Zeno's Paradox". Philosophy and Rhetoric 21 (1988): 145-152. 
RUSSELL, Bertrand. Our Knowledge of the External World. New York, Norton, 1929. Lectures V and VII. SALMON, Wesley. Space, Time and Motjon. Encino, CA: Dickenson, 1975. . ed. Zeno's Paradoxes. Indianapolis: Bobbs, 1970.

SHERRY, David M. "Zeno's Metrical Paradox Revisited". Philosophy of Science 55 (1988): $58-73$.

SORABJI, Richard. "Aristotle on the Instant of Change". Aristotelian Society Supplement 50 (1976): 6989.

SZÉKELY, Laszlô. "Motion and the Dialectical View of the World". Studies in Soviet Thought 39 (1990): 241-255.

TANNERY, Paul. La Géometrie Grecque. Paris: Gauthier-Villars, 1877, 124-125. . Pour l'Histoire de la Science Hellène. Paris: Félix Alcan, 1887, 247-261.

TAYLOR, Richard. "Mr. Wisdom on Temporal Paradoxes". Analysis 14.4 (1952): 15-17.

TE HENNEPE, Eugene. "Language Reform and Philosophical Materialism: Another Round With Zeno". Analysis 23 [Suppl.] (1963): 43-49.

THOMSON, James. "Infinity in Mathematics and Logic". Encyclopedia of Philosophy. Ed. Paul Edwards. London: Macmillan, 1967, v. 4, 183-190.

USHENKO, A. "Zeno's Paradoxes". Mind 55 (1946): 151-165.

WHITE, Michael J. "The Spatial Arrow Paradox". Pacific Philosophical Quarterly 68 (1987): 71-77.

WHITROW, J. G. The Natural Philosophy of Time. London, 1961, 135-137.

WISDOM, J. O. "Achilles on a Physical Racecourse". Analysis 12.6 (1951): 67-72.

ZART, Paulus Johannes. About Time: A Philosophical Inquiry into the Origin and Nature of Time. Oxford: North-Holland, 1976. Ch. XI. 